\title{
Analyzing the multidimensional construction of knowledge in diverse contexts
}

\author{
Gerry Stahl • Ulrike Cress • Nancy Law $\cdot$ Sten Ludvigsen
}

Published online: 22 January 2014

(C) International Society of the Learning Sciences, Inc. and Springer Science+Business Media New York 2014

This year's International Conference of the Learning Sciences (www.isls.org/icls2014) will feature the theme of "practices encompassing the range of contexts and processes in which people learn." In this first issue of 2014 of ijCSCL, we present four explorations of that theme. We begin with a consideration of Activity Theory as a framework for analyzing the systemic contexts of CSCL practices. This is followed by detailed qualitative and quantitative analyses of knowledge building across the age spectrum of schooling: from primary school (4th and 5th grade) to tertiary school (first year college). Finally, the collaborative construction of knowledge is studied at the global level of adults posting to Wikipedia.

In preparation for last year's CSCL conference, a series of editorial introductions to $i j C S C L$ raised the issue of the interrelationships among individual, small-group, and community learning (Stahl 2012, 2013a, b). It is interesting to read the articles in this new issue as in part investigations of such interrelationships. The notion that "interactional resources" such as geometric objects in mathematical problem solving can be seen to be bridging levels of analysis was recently elaborated in (Oner 2013; Stahl 2013c, esp. Ch. 6; Zemel and Koschmann 2013). This notion of resources plays a theoretical role similar to that of artifacts in Activity Theory and appears, for instance, in the scaffolds of epistemic games, the notes of knowledge-building forums and the pivotal-knowledge postings of Wikipedia in the papers of the current issue.

G. Stahl $(\triangle)$

Drexel University, Philadelphia, PA, USA

e-mail: Gerry@ijCSCL.org

U. Cress

Knowledge Construction Lab, KMRC - Knowledge Media Research Center,

Schleichstr. 6, 72076 Tuebingen, Germany

e-mail: Ulrike@ijCSCL.org

N. Law

University of Hong Kong, Hong Kong, People's Republic of China

e-mail: Nancy@ijCSCL.org

S. Ludvigsen

Medical Informatics, University of Oslo, P.O. Box 1080, Blindern, 0316 Oslo, Norway

e-mail: Sten@ijCSCL.org 


\section{Activity Theory}

In her presentation of Activity Theory, Susan Timmis proposes a framework for "understanding the complex interrelations between discourse, actions, and community, and as a result how new technological innovations and knowledge-creation practices can be appropriated and sustained." She thereby references the micro, meso, and macro units of analysis in terms of individuals' actions, small-group discourse, and community practices. Going beyond the usual superficial application of the Activity Theory template to describing CSCL settings, she seeks a path to sustaining CSCL interventions beyond short-term research projects by understanding the dialectical tensions involved in institutionalizing practices through multi-level analysis. This requires studying how micro-level processes can be transformed into persistent macrolevel knowledge-construction practices.

Expanding on Vygotsky's understanding of the role of artifacts, Timmis refers to material "meditational means," which are resources for human activity. She then expands Activity Theory itself to focus more explicitly on dialogicality and communicative action, e.g., small-group interaction, as the intermediate level at which micro and macro are typically bridged: "Agents [individuals] negotiate a shared understanding [group] of the new activities and artifacts, and in this process, new knowledge and practices [community] are created." However, an illustrative multi-level analysis of college students in the UK reveals contradictions - e.g., course assessments opposed individual grades to collaborative work-which militate against sustainability of the educational innovation. Moreover, knowledge-construction practices, relationships, and technologies have important influences on these cross-level systemic tensions.

\section{Knowledge-building games}

Perhaps the most influential approach to CSCL to date has been the theory of knowledgebuilding communities developed by Scardamalia and Bereiter (1996) and their associated Knowledge Forum collaboration environment. Their idea is to introduce students to the knowledge-building practices of academic research communities through collaborative experiences of refining theories of scientific phenomena using an online forum - bridging from the individual learner to the level of science discourse through the intermediate scale of online classroom discussion. Interestingly, the emphasis is not on the students learning facts or playing the roles of scientists as individuals, but on groups of students in a classroom gradually enacting social practices of large communities: "Students learn to use each other's diverse knowledge and skills as resources to collaboratively advance the community's understanding of a problem under investigation."

In their contribution to this issue, Katerine Bielaczyc and John Ow explore how to introduce young students (about 10 years old) in a Singapore classroom to collaborative knowledge building. It is well known from decades of experience using Knowledge Forum in classrooms around the world, that it takes years for teachers, students, schools, and school systems to adopt the necessary philosophy of knowledge building (Chan 2011; Looi et al. 2011). To begin this process with young students, the authors frame the online discussion as a multi-user knowledge-building ("epistemic") game. The game involves progressively improving tentative ideas that the players propose in response to a given topic. In Knowledge Forum, postings are categorized by knowledge-building roles ("my theory," "I need to know," etc.--foreshadowed by Think Cards in the authors' game). Other students can respond to or build on these notes. They can also synthesize sets of notes and 
arrange the notes graphically. Progress in building knowledge takes place through interaction among the notes. Existing notes are interactional resources for the group process of building knowledge through new notes. The categories and interactional moves of the game supported by the software are further resources, which the students must learn to enact effectively. The scientific topic (such as: "How do we know if something is a living thing?") is another resource, which guides a particular group inquiry toward approaching the established theories of the scientific community.

\section{Collective and individual knowledge building}

Ke "Coco" Zhao and Carol K. K. Chan apply a battery of mixed methods to analyzing the knowledge-building achievements of university students in Shanghai, China, using Knowledge Forum (compared to students undertaking similar classroom projects without the CSCL medium). While extending Knowledge Forum research into Chinese tertiary students' understanding of business concepts and academic literacy, the authors support the contention that individual learning and literacy development can be by-products of collective knowledge building. Without fully capturing the mechanisms and resources through which community knowledge diffuses to the participants, they do address whether the CSCL knowledge-building model can affect both collective and individual learning by measuring learning gains at both levels.

The quantitative analysis establishes a relationship between online collective-processing discourse and individual-learning performance. While many coding schemes used in other CSCL studies also include conceptual, collaborative, metacognitive, and social dimensions, this study identifies discourse moves oriented to collective dimensions and meta-discourse in the group. Then it links these processes to individual learning and aligns this with the goal of collective advances in the knowledge-building designs. Members of groups that engaged in meta-discourse scored higher in their individual learning. Analyses of knowledge-building discourse suggest that students' work together can contribute to each other's understanding. As students take up each other's ideas, they weave between individual and group understanding. Student teams often explain, compare, synthesize, and connect different ideas together. Again, the notes posted in Knowledge Forum mediate between individual and collective (team or classroom) knowledge building by means of the practices supported by the software and the pedagogical philosophy underlying it.

\section{Pivotal knowledge in Wikipedia}

We have seen a shift of focus from individual student minds, personalities, and biographies to the artifacts of Activity Theory, the resources of epistemic games, and the notes of Knowledge Forum. While such notes are similar to the utterances that construct knowledge within small groups, articles that are created collectively, like those in Wikipedia, are the product of extended histories of contributions, references, edits, and refinements at the macro level, and cannot be construed as expressions of momentary individual consciousnesses. What are the methodological implications of this for CSCL analysis? Iassen Halatchliyski, Johannes Moskaliuk, Joachim Kimmerle, and Ulrike Cress propose that "in contrast to the analysis of interaction sequences - artifacts and their meaningful interconnected structure offer a unique way of operationalizing knowledge-related processes in collectives. Maintaining the research focus at the intersubjective level, we extend the concept of collective knowledge to long-term 
processes and large-scale network structures." To exemplify this, they investigate the German version of Wikipedia articles categorized as educational and/or psychological.

In Wikipedia, there is very little direct interaction between people or within well-defined groups. Knowledge is constructed through the evolution of interconnected articles. In addition to a proliferation of links relating articles to each other, there is a hierarchical category system in the German Wikipedia (but not in the English one), which structures the evolving mass of articles. Although Wikipedia is not intended to construct new knowledge, but just to introduce and reference existing knowledge, it creates immense amounts of what we might call metaknowledge through its interconnected overall structure. The analysis by Halatchliyski and associates proposes techniques for analyzing the structure of that meta-knowledge at the community level. Using social-network analysis on the links between articles, it defines disciplinary and inter-disciplinary clusters of articles. These clusters, in turn, define different categories of articles, such as pivotal and boundary-spanning articles. The authors then use the results of their analysis at the community level to analyze participation at the individual level of contributors, confirming their hypotheses about different kinds of contributors posting to different categories of articles. One could imagine also analyzing the participation of people in the small-group discussions and differences of opinion that often take place within the evolution of specific articles.

Given the choice of articles (categorized as educational, psychological, and their overlap) in the corpus analyzed, one might guess that the authors had in mind CSCL researchers like themselves. Then the hypothesis would be that contributors to CSCL articles are boundary spanners, who contribute to both educational and psychological articles. However, if one looks at the German Wikipedia, one finds that there is only a brief, largely outdated article on CSCL, with a limited number of links to educational or psychological Wikipedia articles, few researchers contributing, and only a brief, inconclusive discussion (about what to call CSCL in German). Moreover, the German Wikipedia category system itself has no overlap between education and psychology. One wonders what the nature of the articles is that are statistically determined to be boundary spanning in this analysis. Perhaps in addition to the quantitative methods at the different levels one might want to do some qualitative checking on the meaning of findings; otherwise, it is risky to read unwarranted significance into operationalized categories. This is a nice example of how the exploration of an interesting hypothesis about educational research practices requires a carefully designed "multivocality" (Suthers et al. 2013) of methods at different units of analysis.

\section{Epistemic practices}

We started this editorial by relating the papers in this issue to the ICLS 2014 theme, "practices encompassing the range of contexts and processes in which people learn." As we looked at the approaches of the papers to this theme, we began to see that knowledge-building practices have more to do with artifacts, resources, notes, or inscriptions than with the phenomena traditionally associated with people learning, such as thinking, acquiring facts, and mental models. In particular, practices are typically defined at the community unit of analysis and are generally enacted at the small-group, discursive unit. Of course, we are still concerned with learning by individuals and the contributions of individual cognition, so we must investigate the working of these various epistemic or cognitive levels of analysis as they interpenetrate each other. As the articles in this issue illustrate, such an undertaking requires innovative analytic approaches. We have only begun to tease apart and grasp the practices and processes of collaborative learning in an effective multidimensional manner. Perhaps these articles will stimulate ideas about how to do so in preparation for ICLS 2014 and CSCL 2015. 


\section{Resources for CSCL researchers}

ISLS has recently begun the taping of about 50 webinars on topics central to the learning sciences and CSCL, coordinated by Frank Fischer. These 90-min videos are intended primarily for use in college courses within programs on the learning sciences, but are freely available to the public at: http://isls-naples.psy.lmu.de/intro/all-webinars. They feature many prominent researchers in the field discussing with groups of students: how people learn, supporting learning, methodologies for the learning sciences, and computer-supported collaborative learning.

The Springer CSCL book series (http://www.springer.com/series/5814?detailsPage=titles) now offers 15 books, mainly edited volumes on themes of interest to CSCL researchers. The latest release, Productive Multivocality (Suthers et al. 2013), was edited by five members of the ijCSCL Board based on a series of workshops at CSCL and ICLS conferences. The bookseries editors are currently accepting proposals for new monographs or compilations reporting on major CSCL research efforts.

\section{Changes in the $\ddot{i j C S C L}$ Board of Editors}

The $i j C S C L$ Board is continuing to evolve as we begin the 2014 volume. The major change is that Friedrich Hesse has decided to step down from his position as an Executive Editor of ijCSCL. He will remain active on the Board. As you know, Friedrich co-founded the journal in 2005. He collaborated on publishing the eight volumes of the journal to date. Friedrich was a close policy advisor, reviewing every editorial introduction and discussing journal business at the annual CSCL/ICLS conferences. Friedrich provided an essential balance to the journal leadership, which we will maintain in the future with the new changes. Furthermore, KMRCthe research center that Friedrich directs - has contributed many valuable Board members, reviewers, and paper submissions, as well as maintaining the ijCSCL.org website with all our articles freely available to the world in their pre-publication full-text versions.

An additional motivation for Board changes is that as the CSCL field spreads around the world - along with the journal's reputation - the number of submissions is increasing, requiring more reviewers and meta-reviewers.

Ulrike Cress and Sten Ludvigsen have now joined Nancy Law as Executive Editors. In addition to continuing their previous duties as Associate Editors, they will participate in journal leadership tasks. Ulrike leads the Knowledge Construction Lab at KMRC; she authored the popular article on multilevel quantitative analysis (Cress 2008) and the coevolution model of individual and collaborative knowledge construction (Cress and Kimmerle 2008). Sten has long been a leader in the European CSCL community and a representative of the sociocultural tradition in Scandinavia (Furberg et al. 2013). Nancy continues to focus on international educational policy matters and to promote CSCL in Asia.

Expanding the number of Associate Editors, Sanna Järvelä, Peter Reimann, and Baruch Schwarz have agreed to take on this role, joining Carol Chan, Manu Kapur, Carolyn Rosé, and Dan Suthers. That will increase the number of people writing meta-reviews and recommending acceptance of articles from 9 to 11 .

In addition, eight reviewers have agreed to join the Board. They are all CSCL researchers who have completed at least six reviews in the past. We welcome Fengfeng Ke, Oskar Lindwall, Kris Lund, Mingzhu Qiu, Chris Teplovs, Marjaana Veermans, Alyssa Wise, and Coco Zhao to the Board of Editors. They further extend the expertise, diversity, and balance of the Board.

Collectively, we look forward in 2014 to a stimulating ninth volume of ijCSCL in the service of the CSCL research community. 


\section{References}

Chan, C. K. K. (2011). Bridging research and practice: Implementing and sustaining knowledge building in Hong Kong classrooms. International Journal of Computer-Supported Collaborative Learning, 6(2), 147-186.

Cress, U. (2008). The need for considering multilevel analysis in CSCL research: An appeal for the use of more advanced statistical methods. International Journal of Computer-Supported Collaborative Learning, 3(1), 69-84.

Cress, U., \& Kimmerle, J. (2008). A systemic and cognitive view on collaborative knowledge building with Wikis. International Journal of Computer-Supported Collaborative Learning, 3(2), 105-122.

Furberg, A., Kluge, A., \& Ludvigsen, S. (2013). Student sensemaking with science diagrams in a computerbased setting. International Journal of Computer-Supported Collaborative Learning, 8(1), 41-64.

Looi, C. K., So, H. J., Toh, Y., \& Chen, W. L. (2011). The Singapore experience: Synergy of national policy, classroom practice and design research. International Journal of Computer-Supported Collaborative Learning, 6(1), 9-37.

Oner, D. (2013). Analyzing group coordination when solving geometry problems with dynamic geometry software. International Journal of Computer-Supported Collaborative Learning, 8(1), 13-39.

Scardamalia, M., \& Bereiter, C. (1996). Computer support for knowledge-building communities. In T. Koschmann (Ed.), CSCL: Theory and practice of an emerging paradigm (pp. 249-268). Hillsdale: Lawrence Erlbaum Associates.

Stahl, G. (2012). Traversing planes of learning. International Journal of Computer-Supported Collaborative Learning, 7(4), 467-473.

Stahl, G. (2013a). Learning across levels. International Journal of Computer-Supported Collaborative Learning, $8(1), 1-12$.

Stahl, G. (2013b). Transactive discourse in CSCL. International Journal of Computer-Supported Collaborative Learning, 8(2), 145-147.

Stahl, G. (2013c). Translating Euclid: Designing a human-centered mathematics (paperback \& ebook ed.). San Rafael, CA: Morgan \& Claypool Publishers. 221 pages. Web: http://gerrystahl.net/elibrary/euclid.

Suthers, D. D., Lund, K., Rosé, C. P., Teplovs, C., \& Law, N. (Eds.). (2013). Productive multivocality in the analysis of group interactions. New York, NY: Springer. CSCL book series. doi:10.1007/978-1-4614-8960-3.

Zemel, A., \& Koschmann, T. (2013). Recalibrating reference within a dual-space interaction environment. International Journal of Computer-Supported Collaborative Learning, 8(1), 65-87. 